\title{
Currículo e inclusão educacional: percepções de docentes da educação básica
}

\author{
Curriculum and educational inclusion: perceptions of teachers of basic \\ education
}

\begin{abstract}
El currículum y la inclusión educativa: percepciones de los profesores de educación básica
\end{abstract}

\section{Jacqueline Lidiane de Souza Prais ${ }^{1}$}

Universidade Estadual de Londrina

\author{
Hallison Fernando Rosa ${ }^{2}$ \\ Universidade Estadual de Londrina
}

\begin{abstract}
Adriana Regina de Jesus ${ }^{3}$
Universidade Estadual de Londrina, Docente no Curso de Pedagogia e no Programa de Mestrado e Doutorado em Educação
\end{abstract}

Resumo: Neste artigo discutem-se os pressupostos da educação inclusiva e suas implicações para pensar e analisar o currículo escolar. Isso posto, o problema que norteou este estudo teve como questão pensar de que maneira professores da Educação Básica percebem a relação entre o currículo e a inclusão educacional? Justifica-se essa problemática por se entender que quando as intenções inclusivas estão sistematizadas no currículo, as ações docentes propiciam, por meio da organização do ensino, a mediação qualitativa para a aprendizagem dos alunos. Para tanto, teve-se como objetivos: identificar conceitos pertinentes à inclusão e sua relação com o currículo educacional e apresentar e analisar percepções de docentes da Educação Básica, que correspondem, respectivamente, às seções deste artigo. A metodologia utilizada nesta pesquisa tem como pressuposto a abordagem qualitativa, tendo como princípio a pesquisa bibliográfica e de campo, na modalidade descritiva, contando com a participação de 30

\footnotetext{
1 Mestre pelo Programa de Pós-Graduação em Ensino de Ciências Humanas, Sociais e da Natureza da Universidade Tecnológica Federal do Paraná; doutoranda em Educação pela Universidade Estadual de Londrina.

2 Graduado em Licenciatura em Geografia pela Universidade Estadual de Ponta Grossa; mestrando em Educação pela Universidade Estadual de Londrina.

3 Pós-Doutor em Educação pela Universidade Federal Fluminense; Doutor em Educação pela Pontifícia Universidade Católica de São Paulo.
} 
docentes do Município de Londrina, PR. Utilizou-se como instrumento de coleta de dados um questionário analisado em três categorias elencadas a posteriori pela análise de conteúdo. Tem-se como principais resultados e discussão que a maioria dos docentes participantes concebe o currículo como conteúdos a serem ensinados e aprendidos, bem como que o currículo influencia na efetivação ou não da inclusão. Os professores envolvidos nesta pesquisa destacaram, como um dos aspectos a serem abordados por meio do currículo da educação inclusiva, a necessidade de fazer uma avaliação das limitações e possibilidades dos alunos.

Palavras-chave: Currículo. Inclusão educacional. Percepções docentes. Educação Básica. Docentes.

Abstract: This article discusses the assumptions of inclusive education and their implications to think and analyze the school curriculum. That said, the problem that guided this study was thinking about the way that teachers of basic education understand the relationship between the curriculum and the inclusive education? The theme is justified because we believe that when the intentions of inclusive education are systematized in the curriculum, the actions teachers provide, through the organization of education, mediation qualitative research to student learning. Therefore, the study aims to: (i) identify concepts relevant to inclusion and its relationship with the school curriculum, and (ii) present and analyze the perceptions of teachers of basic education, which correspond, respectively, the sections of this article. The methodology used in this study has as a prerequisite the qualitative approach, having with principle bibliographic research and fieldwork in descriptive form, with the participation of thirty (30) teachers of the county of Londrina/Paraná. It was used as an instrument of data collection a questionnaire analyzed in three (3) categories listed retrospectively by content analysis. Has as main results and discussion: that the majority of teachers participating conceives the curriculum as content to be taught and learned, as well as, that the curriculum has an influence on the realization of inclusive education. The teachers involved in this study highlighted, as one of the aspects to be dealt with by means of the curriculum of inclusive education, the need to make an assessment of the limitations and possibilities of the students.

Keywords: Curriculum. Educational inclusion. Teacher perceptions. Basic Education. Teachers.

Resumen: Este artículo analiza los supuestos de la educación inclusiva y sus implicaciones para pensar y analizar el currículo escolar. Dicho esto, el problema que 
guió este estudio tenía como una cuestión de pensar de esa manera los profesores de educación básica comprender la relación entre el currículo y la inclusión en la educación? Este problema está justificada porque cuando las intenciones de inclusión están sistematizados en el currículum, las acciones docentes proporcionar, a través de la organización de la educación, la mediación investigación cualitativa para el aprendizaje del alumno. Por tanto, el estudio pretende: (i) identificar conceptos relevantes para la inclusión y su relación con el currículo de la educación y, (ii) presentar y analizar las percepciones de los profesores de educación básica, que corresponden, respectivamente, en las secciones de este artículo. La metodología utilizada en este estudio tiene como requisito el enfoque cualitativo, teniendo como principio la investigación bibliográfica y de campo, en la modalidad descriptiva, con la participación de treinta (30) profesores del Municipio de Londrina/Paraná. Se utilizó como instrumento de recolección de datos un cuestionario analizado en tres (3) categorías enumeradas, más tarde, por el análisis de contenido. Tiene como principales resultados y discusión: que la mayoría de los profesores participantes concibe el currículo como contenido a ser enseñado y aprendido, así como, que el programa de estudios tiene una influencia en la realización de la inclusión. Los profesores implicados en este estudio destaca, como uno de los aspectos a tratar por medio del curriculum de la educación inclusiva, la necesidad de realizar una evaluación de las limitaciones y posibilidades de los estudiantes.

Palabras clave: Currículum. Inclusión educativa. Percepciones docentes. Educación básica. Profesores.

\section{INTRODUÇÃO}

Todo projeto de educação expressa, sobretudo, um projeto social. É com essa premissa que o papel da escola, do conhecimento e, por sua vez, do currículo deve ser situado. Consequentemente, para constituir um projeto a escola tem sido palco e alvo de disputa de interesses distintos, os quais, por sua vez, expressam os interesses sociais. Assim, todo e qualquer projeto de educação passa, necessariamente, a representar um projeto social movido por uma necessária intencionalidade (SANTOS; LOPES; COSTA, 2017).

Nesse contexto, a inclusão educacional, além de ser prerrogativa constitucional (BRASIL, 1988) que assegura o direito de todos à educação, é um movimento em luta pelo acesso de todos os sujeitos no processo educativo no contexto 
regular de ensino, resultante em um projeto de educação, logo, social (MANTOAN, 2015). Entre os pressupostos de uma educação inclusiva, o acesso à escola regular não está vinculado apenas à matrícula, mas também ao acesso à aprendizagem do conteúdo e, consequentemente, ao currículo escolar.

Cabe mensurar que, diante do contexto da educação inclusiva, surgem terminologias para especificar grupos e singularidades de maior destaque. De um lado, a Declaração de Salamanca (UNESCO, 1994) identifica a abrangência do processo educativo, o qual inclui os alunos com Necessidades Educacionais Especiais (NEE), consistindo em discentes que apresentam necessidades originárias de sua deficiência e/ou de sua dificuldade de aprendizagem. De outro lado, a política brasileira emprega o termo público-alvo da Educação Especial (BRASIL, 1996) para sublinhar a inclusão de aluno com deficiência, alunos com Transtornos Globais do Desenvolvimento e alunos com altas habilidades/superdotação como principal foco da inclusão. Isso porque esse grupo, ou parte dele, foi o que mais sofreu as consequências de um longo período de exclusão no processo de escolarização no ensino regular (BRASIL, 1996). Desse modo, pensar os alunos com NEE e alunos público-alvo da Educação Especial é tomado como ênfase neste artigo diante da proposta de educação inclusiva.

Etimologicamente, currículo vem do latim curriculum (cuja raiz é a mesma de cursus e currere), que significa "pista de corrida” (SACRISTÁN, 2013). Por sua vez, o currículo escolar consiste na seleção intencional de uma porção de cultura. Cultura entendida como a produção humana planificada na forma de conhecimentos, tão logo, de conteúdos a serem ensinados e a serem aprendidos. Portanto, o currículo é entendido como um "território demarcado e regrado do conhecimento correspondente aos conteúdos que professores e centros de educação deveriam cobrir.” (SACRISTÁN, 2013, p. 17).

Nessa perspectiva, para implementação da inclusão educacional é preciso pensar para e na diversidade presente no contexto escolar a fim de satisfazer as necessidades de aprendizagens para que os alunos tenham acesso a esse currículo escolar.

Com base nessas argumentações, neste artigo apresenta-se uma discussão sobre os pressupostos da educação inclusiva e suas implicações para pensar e analisar o currículo escolar. Compreende-se que o professor - por meio de sua prática pedagógica - estabelece diretamente a mediação em uma perspectiva inclusiva com os alunos e permite ou não o acesso a esse currículo. Nesse sentido, acredita-se que quando as 
intenções inclusivas são sistematizadas pelo currículo, as ações docentes podem propiciar, por meio da organização do ensino, a mediação qualitativa para promover a aprendizagem dos alunos. De tal modo, pressupõe-se a relevância de identificar a percepção de docentes - em especial da Educação Básica - sobre essa temática.

Para tanto, esta pesquisa parte do seguinte problema: de que maneira professores da Educação Básica percebem a relação entre o currículo e a inclusão educacional? A fim de responder a essa questão de investigação, definem-se como objetivos: identificar conceitos pertinentes à inclusão e sua relação com o currículo educacional e apresentar e analisar percepções de docentes da Educação Básica que, correspondem, respectivamente, às seções deste artigo.

Como encaminhamento metodológico, emprega-se a pesquisa bibliográfica complementada pela pesquisa de campo nas modalidades qualitativa e descritiva. Utiliza-se como instrumento de coleta de dados um questionário analisado em três categorias elencadas a posteriori pela análise de conteúdo aplicado a 30 docentes da Educação Básica do município de Londrina, PR. Por conseguinte, busca-se apontar uma contribuição ao campo do currículo e da inclusão educacional no contexto da Educação Básica.

\section{CURRÍCULO E INCLUSÃO: RELAÇÕES E PERTINÊNCIA}

Para iniciar a discussão, depreende-se que o planejamento docente é uma ação indispensável para o exercício da docência em uma educação inclusiva. Nessa perspectiva, o currículo é entendido como uma bússola que guia e indica o destino que se almeja. Em outras palavras, o currículo é um ato e um compromisso político e pedagógico diante das intenções com o que se pretende desenvolver (LEAL, 2005). Esse compromisso necessita estar articulado com questões relacionadas à inclusão, uma vez que o currículo é considerado por Silva (2205) como “construção de identidade" e, portanto, necessita ser organizado de maneira contextualizada, tendo como parâmetro o princípio de inclusão.

Segundo Grundy (1998), o currículo não é um conceito, mas uma construção cultural. Isto é, não se trata de um conceito abstrato que tenha algum tipo de existência fora e previamente à experiência humana. É, antes, um modo de organizar uma série de práticas políticas educativas. 
Assim, deve-se pensar o currículo a partir da realidade local da escola. Transformar o currículo em um documento baseado em ideias oriundas de modelos que, aparentemente, são declarados como casos de sucesso em outras realidades não é suficiente para garantir que tal modelo traga resultados positivos. $\mathrm{O}$ fato de considerar a realidade cultural do espaço onde determinada escola está, verificando quem são os alunos e professores que ali estão, quais as suas condições socioeconômicas, qual a influência da comunidade no âmbito escolar, entre outras ações, revela a construção de um currículo voltado à inclusão.

Schubert (1986 apud SACRISTÁN, 1999) afirma que, em termos globais, os conceitos de currículo emergem como imagens, algumas vezes contraditórias entre si, afirmando tratar-se de um conjunto de conhecimentos a serem superados pelo aluno dentro de um ciclo; ou como um programa de atividades ordenadas em um manual ou guia para o professor e, ainda, com conteúdos e valores para que os alunos melhorem a sociedade.

De fato, o currículo é visto como o guia para as práticas pedagógicas. Entretanto, não se pode encarar a educação inclusiva por meio de regras e ações que trarão resultados pré-estabelecidos. Em análise às afirmações de Leal (2005), Moreira e Candau (2003) e Schubert (1986 apud SACRISTÁN, 1999), chega-se à compreensão de um consenso para o currículo: existe uma relação estreita entre o currículo e as práticas educativas e é por meio dele que as funções básicas da escola se realizam.

Ou seja, as escolas estão presas às regras de um documento considerado o responsável pelo que se deve ou não fazer. Para que isso mude, é preciso compreender que não há um modelo correto para que todos os alunos de uma escola aprendam e se desenvolvam. Quando se fala de diversidade de alunos, o resultado é inesperado. Trata-se de alunos com níveis de aprendizagem diferentes. Sobretudo, a forma como isso será encarado pelos profissionais da educação é que fará a diferença.

De acordo com Moreira e Candau (2003), diferentes fatores sociais e culturais contribuem para que o currículo seja entendido como: conteúdos a serem ensinados e aprendidos; experiências de aprendizagens a serem vividas; planos pedagógicos a serem elaborados pelos professores, escolas e sistemas educacionais; objetivos a serem alcançados por meio do processo de ensino; e processos de avaliação.

Considerando os fatores que implicam a construção de currículos educacionais em nosso país, e verificando que nosso sistema atual revela grandes falhas na educação para todos os indivíduos, é preciso pensar em um projeto de sociedade mais 
justa, com justiça e equidade. Assim, a questão central é saber qual conhecimento deve ser ensinado, haja vista o currículo pensado em uma perspectiva inclusiva.

Isso revela, portanto, a pertinência de um currículo inclusivo. É preciso prover mudanças pedagógicas para assegurar o direito de todos à educação. Para tanto, é necessária a oportunidade para reflexão, análise e interpretação de sua própria atuação como docente.

Como já dito, não há um modelo específico para a construção de um currículo inclusivo. Mas há ações importantes que podem ser pensadas no processo de atuação docente para que a forma de educação atual abranja, realmente, todos os alunos. É o que propõe Melero (2013), a partir do enfoque histórico-cultural, ao trazer cinco estratégias didáticas para que se construa um currículo sem exclusões.

Primeiramente, é preciso que se devolva a todos os alunos o seu direito de aprender. Postula-se que todos têm direito à educação, mas o que se percebe é que as exclusões são reais. Ou seja, é preciso reverter esse quadro por meio de estratégias que garantam tal direito. É assim que a segunda estratégia é contemplada: a de que os professores aprendem enquanto ensinam. Nesse ponto, há que se considerar o rompimento com o modelo tradicional de ensino, no qual o professor é detentor de todo o conhecimento e desconhece salas heterogêneas, e o aluno é o mero receptor e sua realidade tem importância ínfima. Assim, chega-se à terceira estratégia, que é a aprendizagem dialógica, em que os sujeitos se desenvolvem por meio da conversação e interação. Isso remete diretamente à quarta estratégia, a qual revela uma aprendizagem cooperativa e solidária em busca de um ponto em comum: o desenvolvimento. Por fim, a quinta estratégia caracteriza-se com o compromisso da ação docente além de seu discurso teórico, sendo, portanto, responsável pelo currículo inclusivo e refletindo as práticas a fim de atendê-lo (MELERO, 2013).

Garantir uma educação inclusiva é um processo de reflexão constante, o qual demanda cuidado. Os profissionais da educação devem estar sujeitos às mudanças que as salas de aula e instituições de ensino impõem direta e indiretamente. Portanto, muito mais que o conjunto das atividades nucleares da escola, o currículo é a própria expressão das intenções dela. Muito mais que um projeto de escola, essas intenções refletem, ou deveriam refletir, um projeto de sociedade. Nesse sentido, ele expressa um caminho pelo qual, teoricamente, todos deveriam percorrer rumo a esse projeto social.

Em síntese, o currículo é uma seleção, sim, de conteúdos, de concepções e de intenções, os quais devem ser democratizados para toda a população, uma vez que 
são requisitos mínimos para a participação consciente em uma sociedade cada vez mais excludente, seletiva e contraditória.

\section{ENCAMINHAMENTO METODOLÓGICO}

Tendo como objetivo compreender as percepções docentes sobre a relação entre currículo e inclusão na Educação Básica, selecionou-se a pesquisa bibliográfica complementada pela pesquisa de campo na modalidade descritiva.

De acordo com Lüdke e André (2012), a pesquisa bibliográfica é desenvolvida com base em produções científicas elaboradas a partir do tema definido pelo pesquisador para sua consulta e análise. Nesse sentido, busca-se levantar pesquisas sobre o tema, verificar as diferentes contribuições científicas, bem como analisar os conceitos apresentados nestes textos, entre eles livros e artigos.

Entre os tipos de pesquisa de campo, optou-se pela qualitativa descritiva que, segundo Lüdke e André (2012), permite ao pesquisador descrever as características de determinadas populações ou fenômenos e analisar com base no referencial encontrado na pesquisa bibliográfica. Uma de suas peculiaridades está na utilização de técnicas padronizadas de coleta de dados, como o questionário.

Nesse sentido, para coleta dos dados, empregou-se como instrumento o questionário, que corresponde a uma "[...] técnica de investigação composta por um número mais ou menos elevado de questões apresentadas por escrito às pessoas, tendo por objetivo o conhecimento de opiniões, crenças, sentimentos, interesses, expectativas, situações vivenciadas, etc.” (GIL, 1999, p. 128).

$\mathrm{Na}$ pesquisa de campo, delimitou-se como o lócus de pesquisa instituições de ensino do Município de Londrina e, como participantes, os professores que estariam atuando na Educação Básica (Educação Infantil, Anos Iniciais do Ensino Fundamental, Anos Finais do Ensino Fundamental e Ensino Médio - sendo que este último poderia ser na modalidade profissionalizante). O questionário foi composto por nove questões, sendo três fechadas (objetivas) e seis abertas (dissertativas), contemplando: a formação profissional do docente (fechada); a especificação das áreas de formação (aberta); a etapa da Educação Básica em que atua (fechada); o tempo de exercício como docente (aberta); a concepção sobre currículo e sua representação na escola (aberta); se a organização do currículo favorece ou não a inclusão (fechada); a avaliação do docente sobre o currículo na instituição em que trabalha (aberta); 
elementos a serem considerados na construção do currículo inclusivo (aberta); e demais apontamentos que o entrevistado considere importante (aberta).

Para aplicação do instrumento de coleta de dados, optou-se por disponibilizar o questionário no Google Forms, que se refere a um dos aplicativos que faz parte do Google Drive, no qual é possível criar questionários e coletar informações de forma simples e rápida on-line. O link de acesso ao questionário foi enviado por e-mail a professores de escolas públicas que atendiam aos critérios estabelecidos. Para isso, contatamos a Secretaria Municipal de Educação de Londrina e o Núcleo Regional de Educação do mesmo Município, solicitando o e-mail das escolas. A estas foi explicada a pesquisa e solicitadas indicações de professores que atendiam aos critérios e que pudessem representar a instituição respondendo ao questionário.

Teve-se a participação de 30 docentes de escolas públicas que receberam e devolveram o questionário respondido. A partir disso, para assegurar o sigilo da identidade dos participantes, os professores são reportados com a utilização da letra D (docente) seguida da numeração aleatória dos questionários, exemplificado por D01 até D30.

Para análise dos dados, empregou-se a análise de conteúdo, conforme Bardin (2011, p. 44), que se refere “[...] um conjunto de técnicas de análises das comunicações que utiliza procedimentos sistemáticos e objetivos de descrição do conteúdo das mensagens." A partir dos dados, foram elencadas três categorias a posteriori de análise, sendo elas: perfil dos participantes; percepções conceituais de currículo; e percepções sobre o currículo na perspectiva inclusiva.

\section{RESULTADOS E DISCUSSÕES}

\subsection{PERFIL DOS PARTICIPANTES}

Nesta primeira categoria de análise, apresentam-se os dados referentes ao perfil dos participantes coletados da primeira à quarta questão do questionário.

No que se refere à formação profissional dos 30 participantes da pesquisa, são professores com diferentes níveis. Considerando a titulação mais alta, 20\% (6) possuem mestrado, 66,7\% (20) possuem especialização, e 13,3\% (4) possuem graduação. 
Gráfico 1 - Formação profissional considerando a titulação mais alta

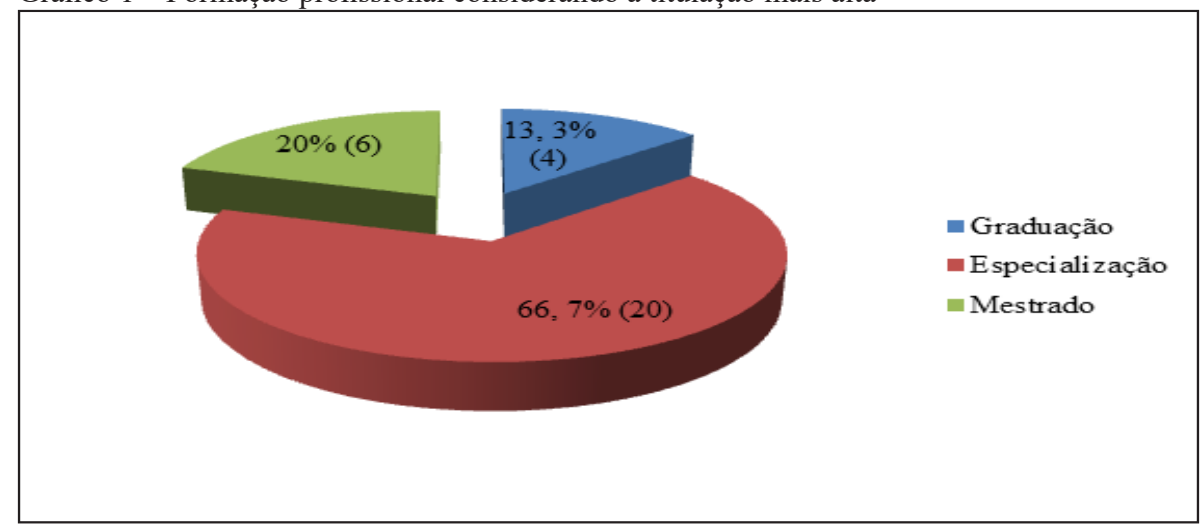

Fonte: os autores.

Além disso, no Gráfico 2 aponta-se a etapa da Educação Básica em que atuam os docentes participantes desta pesquisa.

Gráfico 2 - Especificação da atuação dos participantes na Educação Básica

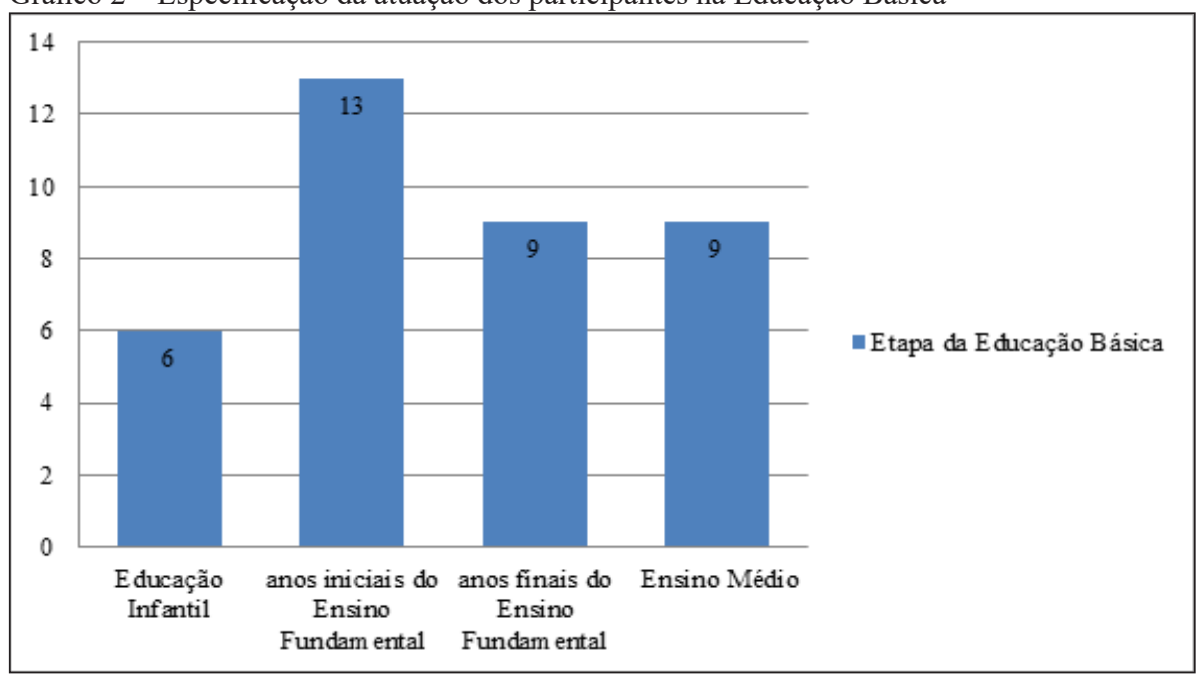

Fonte: os autores.

Esclarece-se que, conforme exemplificado no Gráfico 2, dos 30 docentes participantes: 20\% (6) são professores na Educação Infantil, 43,3\% (13) atuam nos anos iniciais do Ensino Fundamental, 30\% (9) são professores nos anos finais do Ensino Fundamental e 30\% (9) atuam no Ensino Médio (10\% (3) destes últimos são 
professores no Ensino Médio na modalidade de Educação Técnico-Profissional). Observa-se que a porcentagem supera os $100 \%$, pois $20 \%$ (6) dos docentes atuam em mais de uma etapa da Educação Básica: D15 é docente nos anos iniciais e nos anos finais do Ensino Fundamental, D17 atua nos anos finais do Ensino Fundamental e no Ensino Médio, D18, D24 e D30 atuam nos anos finais do Ensino Fundamental e no Ensino Médio, e D25 é docente nos anos finais do Ensino Fundamental, no Ensino Médio e na Educação Técnico-Profissional em nível médio.

No que diz respeito ao tempo de exercício como docente, obteve-se como média aproximada 11 anos de atuação profissional, sendo a menor de um ano e a maior de 35 anos.

\subsection{PERCEPÇÕES CONCEITUAIS DE CURRÍCULO}

Nesta categoria são apresentadas as percepções docentes quanto ao conceito de currículo, sua representação na escola e se a maneira com que o currículo escolar é organizado pode favorecer ou não a inclusão educacional.

No que diz respeito à conceituação de currículo e o que ele representa dentro da escola, retomaram-se as cinco indicações mais comuns apresentadas por Moreira e Candau (2003) para leitura e análise das respostas obtidas dos docentes participantes. A partir disso, utilizaram-se as indicações desses autores somadas a mais duas categorias encontradas nas percepções conceituais no registro escrito da fala dos professores. A categorização dessas sete unidades de análise é apontada e sistematizada na Tabela 1. 
Tabela 1 - Categorização das conceituações de currículo pelos participantes

\begin{tabular}{|c|c|c|c|}
\hline Categorias & $\begin{array}{c}\text { Classificação das falas es- } \\
\text { critas dos participantes }\end{array}$ & $\begin{array}{l}\text { Frequência } \\
\qquad\left(n^{0}\right)\end{array}$ & $\begin{array}{c}\text { Porcentagem } \\
(\%)\end{array}$ \\
\hline $\begin{array}{l}\text { Conteúdos a serem ensinados } \\
\text { e aprendidos }\end{array}$ & $\begin{array}{c}\text { D01, D02, D06, D07, D10, } \\
\text { D11, D13, D17, D23, D24, } \\
\text { D27, D28 e D30 }\end{array}$ & 13 & 40,6 \\
\hline $\begin{array}{l}\text { Experiências de aprendiza- } \\
\text { gens vivenciadas e a serem } \\
\text { vividas }\end{array}$ & D17 e D25 & 2 & 6,3 \\
\hline $\begin{array}{l}\text { Planos pedagógicos a serem } \\
\text { elaborados pelos professores, } \\
\text { escolas e sistemas educa- } \\
\text { cionais }\end{array}$ & D12 & 1 & 3,1 \\
\hline $\begin{array}{l}\text { Objetivos a serem alcança- } \\
\text { dos por meio do processo de } \\
\text { ensino }\end{array}$ & D26 & 1 & 3,1 \\
\hline Processos de avaliação & D20 & 1 & 3,1 \\
\hline $\begin{array}{l}\text { A identidade de cada institui- } \\
\text { ção em sua função social }\end{array}$ & D03, D04 e D18 & 3 & 9,4 \\
\hline $\begin{array}{l}\text { Documento orientador da } \\
\text { prática pedagógica }\end{array}$ & $\begin{array}{c}\text { D05, D07, D08, D09, D14, } \\
\text { D15, D16, D19, D21, D22 } \\
\text { e D29 }\end{array}$ & 11 & 34,4 \\
\hline
\end{tabular}

Fonte: os autores.

Ao analisar a distribuição das falas escritas dos participantes nas categorias apresentadas na Tabela 1, dois docentes (D07 e D17) deram respostas que se classificam em mais de uma categoria. Assim, a frequência ultrapassa o número de 30 docentes, sendo a porcentagem calculada a partir do total de 32 frequências.

Tem-se a prevalência $(40,6 \%)$ de que o currículo escolar é o orientador para conteúdos que são ensinados e aprendidos no processo educacional. Como argumentam os participantes D06 e D10, respectivamente: "são os conteúdos que a escola ensina" e "currículo é a linha mestra a ser seguida e representa a organização dos conteúdos na escola." (informações verbais).

Sabe-se, portanto, que a escola é a representação de algum modelo adotado com vistas à formação de indivíduos, considerando que o:

Currículo escolar é o conjunto de conhecimentos científicos historicamente acumulados que um grupo escolheu tendo como parâmetro um modelo de homem e sociedade com o qual este 
currículo deve contribuir para a formação dos cidadãos. Reflete respostas ao por quê, para quê, quando e como dos processos educativos. (D01, informação verbal).

Nesse sentido, a escola propõe, por meio do currículo, uma formação que contemple a natureza do ser humano e vise à contextualização da sociedade atual em que está inserida. Assim, uma de suas funções é a:

[...] identificação dos elementos culturais que devem ser organizados e assimilados por indivíduos da espécie humana para que se tornem humanos (daí a importância dos processos de seleção, organização e distribuição do conhecimento e da cultura) e, por outro lado e, concomitantemente, ao descobrimento das formas mais adequadas para se chegar a esse objetivo. Essa é a referência para a organização e o funcionamento do sistema escolar e de toda a problemática curricular. (FUENTE, 2011, p. 9 , tradução nossa).

Ou seja, os conteúdos ensinados e aprendidos devem mostrar uma relação com a cultura da sociedade, a qual estará impregnada de significações de um grupo que deverá ser analisado e considerado em planejamentos pedagógicos.

Nessa perspectiva, Santos e Costa (2017, p. 91) abordam que as discussões atuais em torno do currículo ressaltam a necessidade de análises mais críticas e significativas da realidade em que estão inseridos e, assim, “[...] é necessária uma formação para além do senso comum, uma vez que, por meio desta, é possível desenvolver autonomia intelectual e consciência social diante dos fatos apresentados de forma tão naturalizada pela sociedade atual." Dessa forma, tem-se na categoria Experiências de aprendizagens vivenciadas e a serem vividas, da Tabela 1, a afirmação de que:

O currículo escolar se baseia no planejamento pedagógico do professor e este pode sofrer alterações. Dentro da escola ele representa experiências vividas, que tanto o professor e o aluno vivenciam. Essas experiências são resultados dos conhecimentos adquiridos, supostamente por meio de conteúdos apresentados no planejamento pedagógico elaborado pelo docente. (D25, informação verbal).

Sendo as práticas pedagógicas coerentes ao planejamento, Sacristán (2000, p. 102) afirma que essas devem ser analisadas "não como um objeto estático, mas como a expressão de um equilíbrio entre múltiplos compromissos. E mais uma vez esta é condição crucial tanto para compreender a prática escolar vigente como para tratar de mudá-la." 
Ao considerar o currículo relacionado com planos pedagógicos a serem elaborados pelos professores, escolas e sistemas educacionais, destaca-se a fala de D12, que afirma que o currículo "É uma organização necessária dentro do sistema para nortear o trabalho docente.” (informação verbal). Nesse sentido, a elaboração do currículo está permeada pelas concepções adotadas e a serem seguidas pelos docentes em sala de aula.

Outro aspecto conceitual que apareceu na fala dos participantes foi a relação do currículo com o sentido de consistir em objetivos a serem alcançados por meio do processo de ensino. Tal prerrogativa é exemplificada pela fala escrita do participante D26, quando declara que: “O currículo é um documento em que se organiza as áreas do conhecimento e os conteúdos a serem ensinados. Ele representa o objetivo de ensinar conhecimentos escolares." (informação verbal).

O currículo também foi percebido como processo de avaliação, conforme indicação do D20, que sinaliza que é "Uma ferramenta necessária para a organização dos conteúdos dentro de uma escola e acima de tudo a garantia de proporcionar aos alunos um ensino de qualidade.” (informação verbal). O destaque aqui é a palavra "garantia", enfatizada pelo docente como sendo o currículo aquele que garante, por meio da avaliação, a qualidade do processo de ensino.

Dentre as categorizações conceituais dadas pelos participantes, o currículo foi relacionado à identidade de cada instituição em sua função social.

\footnotetext{
O currículo escolar é a identidade da instituição de como se caracteriza e organiza suas ações pedagógicas. Qual sua visão de homem, qual seu papel na sociedade. (D03).

O currículo representa a identidade da instituição pela qual ela expressa a organização do seu trabalho pedagógico e como irá cumprir sua função social de ensinar os conhecimentos para os alunos. (D04).

Ele representa uma estrutura, aquilo que será colocado para os estudantes e toda equipe de funcionários. Seria uma espécie de identidade da escola. (D18) (informações verbais).
}

Os posicionamentos dados pelos participantes D03, D04 e D18 corroboram a ideia apontada por Silva (2005) de que o currículo também consiste na construção de identidade e, portanto, nele se expressa a concepção de homem, de sociedade e de educação que indicará o caminho a ser seguido pela instituição em sua prática pedagógica. 
Por fim, a última categoria, dentre as conceituações dadas ao currículo pelos participantes, teve destaque, com 34,4\% (11) de frequência, o currículo entendido como documento orientador da prática pedagógica.

Ele é a organização do trabalho pedagógico de uma escola contendo os conteúdos, as disciplinas, os objetivos e a avaliação. Ele representa um documento importante utilizado pelos professores para orientar nossa prática pedagógica. (D05).

Currículo é o caminho pedagógico a ser seguido pelo professor e todos da escola. Dá os limites do ponto de saída e chegada de cada série sobre nível de conhecimento a ser trabalhado. (D21). Currículo é o que norteia o trabalho do professor e o que direciona as ações pedagógica. (D22).

Organização para trabalho pedagógico. (D29) (informações verbais).

Ao que propõem os docentes supracitados, o currículo é constituído de um documento que possui relação direta com as práticas a serem exercidas. Não obstante, concordam com Brito (2014, p. 70) quando este afirma que "[...] o currículo escolar é algo indispensável e indissociável das práticas docentes isso leva a crer que não há escola sem currículo, sendo este instrumento, o eixo norteador do fazer pedagógico."

Os dados das respostas à questão Em sua opinião, a maneira com que o currículo escolar é organizado pode favorecer ou não a inclusão educacional? são apresentados no Gráfico 3, que indica a percepção dos docentes sobre se a organização do currículo favorece ou não a inclusão.

\section{Gráfico 3 - Percepção docente sobre o currículo e a inclusão educacional}

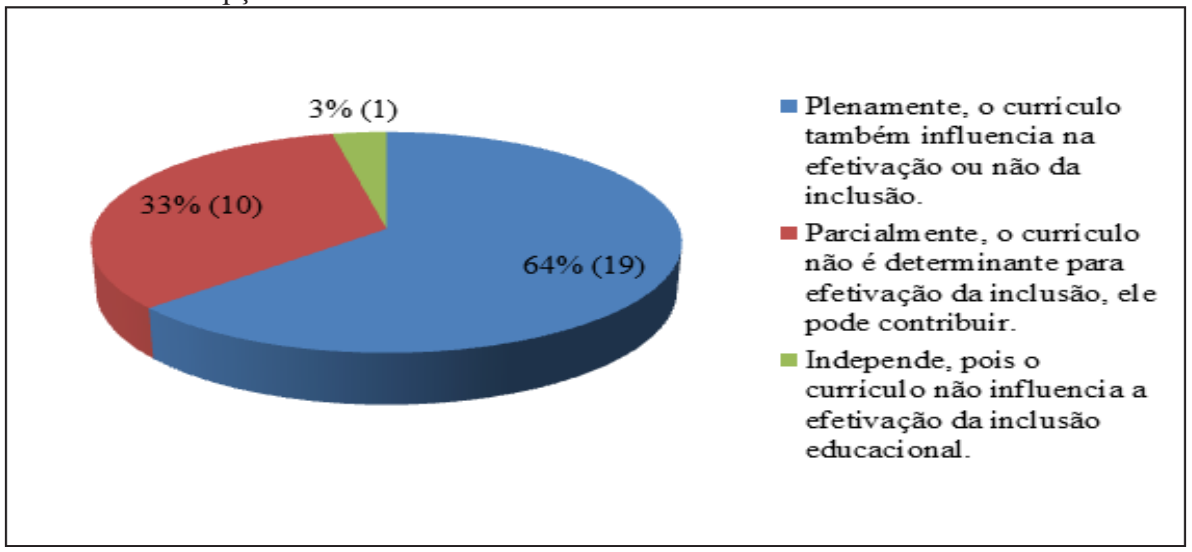

Fonte: os autores. 
Conforme as respostas obtidas dos participantes, 64\% (19) consideram que, plenamente, o currículo também influencia na efetivação ou não da inclusão. Outros 33\% (10) avaliaram que parcialmente, considerando que o currículo não é determinante para efetivação da inclusão, mas que ele pode contribuir. E apenas $3 \%$ (1) avaliou que é independente, pois o currículo não influencia a efetivação da inclusão educacional.

Ao se pensar a inclusão e as práticas pedagógicas, de que maneira poderia se efetivar a ação docente na inclusão de todos os alunos de uma escola? Ao que trata a Declaração de Salamanca, em 1994:

Princípio fundamental da escola inclusiva é o de que todas as crianças devem aprender juntas, sempre que possível, independentemente de quaisquer dificuldades ou diferenças que elas possam ter. Escolas inclusivas devem reconhecer e responder às necessidades diversas de seus alunos, acomodando ambos os estilos e ritmos de aprendizagem e assegurando uma educação de qualidade à todos através de um currículo apropriado, arranjos organizacionais, estratégias de ensino, uso de recurso e parceria com as comunidades. Na verdade, deveria existir uma continuidade de serviços e apoio proporcional ao contínuo de necessidades especiais encontradas dentro da escola. (UNESCO, 1994, p. 5, grifo nosso).

Portanto, os currículos escolares são considerados nos pressupostos da educação inclusiva, os quais devem estabelecer relações com as demais ações para que a inclusão seja efetiva. Sobretudo, ao que enfatiza Ainscow (2008), é preciso identificar e superar as barreiras que impeçam os conhecimentos de serem adquiridos pelos alunos. Dentre elas, o próprio currículo.

Assim, o currículo escolar não é compreendido como mero contribuinte da inclusão, mas, principalmente, como articulador entre práticas pedagógicas, contextos educacionais, sociais e culturais, objetivando a inclusão e, consequentemente, a aprendizagem de todos os alunos. Não obstante, “[...] podemos dizer que as práticas curriculares articulam elementos que existem no mundo, ao mesmo tempo em que criam sentidos para o mundo ocupando uma posição central nos processos de inclusão escolar.” (TRAVERSINI et al., 2013, p. 15-16).

Considerando a importância da educação inclusiva na justiça social, é preciso se pensar como os 64\% (19) participantes do Gráfico 3 que responderam acerca da importância plena do currículo na efetivação ou não da inclusão. Por conseguinte, 
Argumentamos que na escola contemporânea o currículo, necessariamente, precisa ser pensado, discutido e viabilizado na perspectiva da inclusão e da exclusão, numa dimensão relacional, por isso o compreendemos como um processo de in/exclusão. Em se tratando de tal perspectiva, é importante pensar as práticas pedagógicas imersas na complexidade de uma escola que, sob o imperativo da inclusão, precisa abrir-se para incluir a todos/as e, ao mesmo tempo, enfrentar limitações de todas as ordens que impedem o acesso com garantia de qualidade nas inclusões que promove. (TRAVERSINI et al., 2013, p. 16).

Com base nessa discussão, entende-se que o currículo inclusivo exige um olhar universal à diversidade. Beneficiar a educação, os alunos e o próprio trabalho depende das escolhas e práticas pedagógicas que serão adotadas, a começar pela construção do currículo.

\subsection{PERCEPÇÕES SOBRE O CURRÍCULO NA PERSPECTIVA INCLUSIVA}

Nesta categoria, apresentam-se as percepções docentes quanto à relação entre currículo e educação inclusiva obtidas por meio das questões 7 e 8 do instrumento de coleta de dados (questionário).

No Gráfico 4, aponta-se a avaliação dos docentes sobre o currículo da instituição em que trabalham em relação aos pressupostos de uma educação inclusiva.

Gráfico 4 - Percepção docente sobre o currículo da instituição em que atua referente aos pressupostos da inclusão educacional

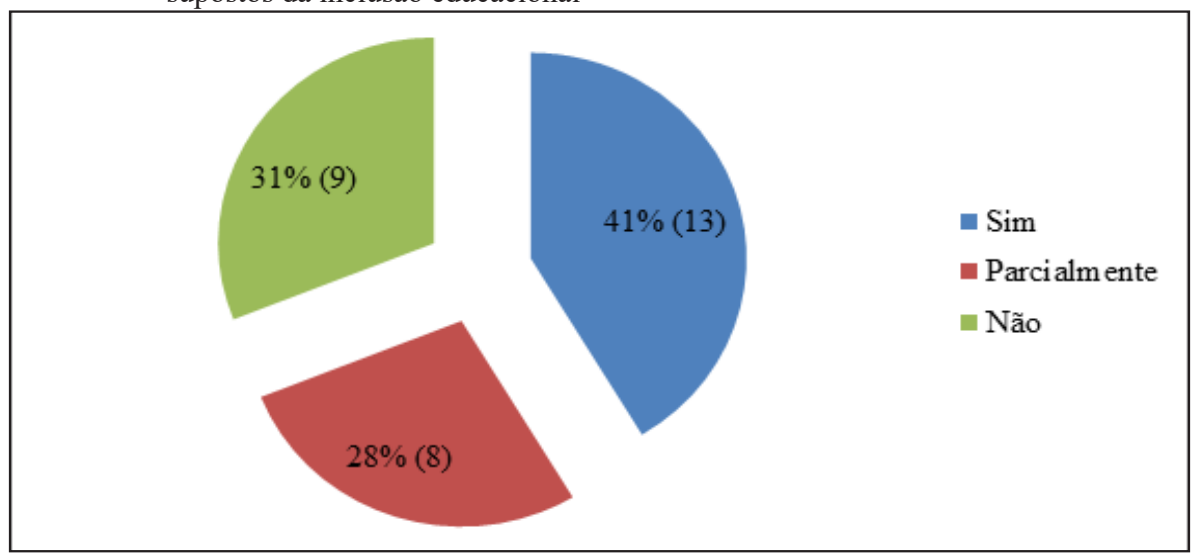

Fonte: os autores. 
Conforme os dados obtidos, a maioria dos docentes $41 \%$ (13) considera que o currículo de sua instituição contempla os pressupostos de uma educação inclusiva, seguidos de $31 \%$ (9) que avaliam que o currículo não os contempla. Por fim, 28\% (8) consideram que ele os contempla parcialmente.

Diante dessas respostas, apresentam-se a seguir algumas justificativas dadas pelos docentes em cada uma dessas avaliações para exemplificar suas percepções em relação ao currículo e à pertinência com a inclusão educacional.

Quadro 1 - Justificativa de docentes em relação à avaliação do currículo e à presença dos pressupostos inclusivos

\begin{tabular}{|l|l|}
\hline $\begin{array}{c}\text { Critério de } \\
\text { avaliação }\end{array}$ & \multicolumn{1}{c|}{ Justificativa do docente } \\
\hline Sim & $\begin{array}{l}\text { D05: Acredito que sim. Pois indica que para alunos com deficiência e com } \\
\text { dificuldade precisamos adaptar as atividades, tem o apoio especializado tam- } \\
\text { bém. E também acredito que o currículo ajuda a definir o que ensinar e cada } \\
\text { professor pode organizar suas atividades de acordo com seus alunos. } \\
\text { D07: Penso que o currículo seja a concepção de educação. Então acho que } \\
\text { no papel está muito bonito, tem os pressupostos da inclusão, mas na prática, } \\
\text { como professora, penso que não temos formação suficiente para trabalhar no } \\
\text { contexto da inclusão. } \\
\text { D20: Adequado e que atende às necessidades dos alunos. Sim, e nos dá direi- } \\
\text { to de fazer as devidas modificações pensando nas características dos alunos } \\
\text { em questão. } \\
\text { D25: Flexível e contempla pressupostos de uma educação inclusiva. } \\
\text { D26: Acho que temos uma ótima organização curricular, porém penso que } \\
\text { quanto à educação inclusiva ainda falta atrelar como o professor vai trabalhar } \\
\text { isso na prática de sala de aula. Acho que assegurar o direito de todos à educa- } \\
\text { ção é um grande desafio, pois a escola historicamente não está preparada para } \\
\text { isso. Eu inclusive não me sinto preparado e nem com formação adequada } \\
\text { com alunos que possuem alguma deficiência ou dificuldade mais grave de } \\
\text { aprendizagem. (informações verbais). }\end{array}$ \\
\hline
\end{tabular}




\begin{tabular}{|l|l|}
\hline $\begin{array}{c}\text { Critério de } \\
\text { avaliação }\end{array}$ & \multicolumn{1}{c|}{ Justificativa do docente } \\
\hline \multirow{5}{*}{ Parcialmente } & $\begin{array}{l}\text { D01: O currículo oficial contempla muito pouco os pressupostos da EI uma } \\
\text { vez que privilegia os resultados em detrimento do processo e das singularida- } \\
\text { des de cada aluno, contudo, os professores têm se esforçado para que o pro- } \\
\text { cesso seja valorizado no currículo em ação e, desta forma, tornam o currículo } \\
\text { mais inclusivo em função das suas práticas pedagógicas. } \\
\text { D12: Na verdade ele deixa um pouco a desejar, poderia ser melhor construído } \\
\text { D23: Penso que ele contempla alguns princípios, mas ainda faltam elementos } \\
\text { para orientar os professores no contexto da inclusão. } \\
\text { D27: Acredito que muito pouco, nesse momento o currículo está em fase de } \\
\text { reelaboração, mas acredito que não contempla a educação inclusiva, ficando } \\
\text { a cargo do professor essa tarefa. } \\
\text { D28: É um bom currículo. Mas acredito que ainda falta aprofundar com } \\
\text { relação à educação inclusiva. (informações verbais). }\end{array}$ \\
$\begin{array}{l}\text { D03: Não, o currículo é pensado para outros alunos. Quando a criança tem } \\
\text { alguma necessidade especial as professoras fazem uma falsa adaptação, para } \\
\text { a secretaria e os pais não reclamarem. } \\
\text { D04: Penso que ele não expressa os encaminhamentos pedagógicos inclusi- } \\
\text { vos, pois indica metodologias e recursos que não atende às necessidades de } \\
\text { todos alunos. } \\
\text { D11: Penso que não, pois não apresenta orientações para os professores ensi- } \\
\text { narem os conteúdos para alunos com deficiência. } \\
\text { D17: O currículo escolar do Estado do Paraná é muito confuso. Não acredito } \\
\text { que ele auxilie plenamente a educação inclusiva. (informações verbais). }\end{array}$ \\
\hline
\end{tabular}

Fonte: os autores.

As escolas públicas brasileiras mostram-se, em contexto geral, desumanas. O currículo escolar destas foi pensado de maneira equivocada, sem corresponder à multiculturalidade do país e sem compreender a realidade histórico-política. Em muitos casos, não é assimilado pelos profissionais da educação que, envoltos de suas práticas, ministram por correntes de pensamentos opostas às quais o currículo está fundamentado. Isso quando o próprio currículo não engloba bases teóricas e estratégias diversas. Então, como as escolas públicas do País se tornariam humanas? Melero (2013, p. 398) diz que "[...] é preciso que a escola se reconstrua e se transforme em função da diversidade."

É a respeito dessa diversidade que o currículo inclusivo propiciará a todos os indivíduos uma educação justa. Quando se verificam as respostas dos docentes D03, D04, D11 e D17 do Quadro 1, percebe-se que o currículo não está contemplando 
práticas inclusivas e que, para que elas ocorram, o professor em sala torna-se o único efetivador destas. Entretanto, é preciso pensar que as ações de uma

[...] escola cuja orientação seja inclusiva enfatizam uma postura não só dos educadores, mas de toda a comunidade educacional e de todo o sistema educacional. Uma escola com orientação inclusiva é aquela que se preocupa com a modificação da estrutura, do funcionamento e da resposta educativa que se deve dar a todas as diferenças individuais, em qualquer instituição de ensino, de qualquer nível educacional. (SANTOS, 2009, p. 14).

No que se refere à percepção dos docentes quanto aos elementos a serem considerados na construção do currículo inclusivo, identificaram-se sete aspectos apontados por eles que guiaram a categorização das falas escritas (Tabela 2).

Tabela 2 - Percepção dos docentes quanto aos elementos a serem considerados na construção do currículo inclusivo

\begin{tabular}{|c|c|c|c|}
\hline Elementos - categorias & Menção por participante & $\begin{array}{c}\text { Frequência } \\
\text { (n.) }\end{array}$ & $\begin{array}{c}\text { Porcentagem } \\
(\%) \\
\end{array}$ \\
\hline $\begin{array}{l}\text { Possibilitar a avaliação das } \\
\text { limitações e possibilidades dos } \\
\text { alunos }\end{array}$ & $\begin{array}{l}\text { D01, D03, D09, D10, D12, } \\
\text { D15, D17, D18, D20, D21, } \\
\text { D22, D25, D27 e D29 }\end{array}$ & 14 & 46,7 \\
\hline $\begin{array}{l}\text { Abordar questões relativas à rea- } \\
\text { lidade da escola e da diversidade } \\
\text { no contexto escolar }\end{array}$ & $\begin{array}{c}\text { D02, D04, D07, D14, D19, } \\
\text { D24 e D30 }\end{array}$ & 7 & 23,4 \\
\hline $\begin{array}{l}\text { Indicar conceitos e metodologias } \\
\text { adequadas para a inclusão }\end{array}$ & D05, D11, D23 e D28 & 4 & 13,3 \\
\hline $\begin{array}{l}\text { Orientar a elaboração de currícu- } \\
\text { lo adaptado }\end{array}$ & D06 & 1 & 3,3 \\
\hline $\begin{array}{l}\text { Ressaltar a necessidade de uma } \\
\text { construção coletiva }\end{array}$ & D08 & 1 & 3,3 \\
\hline $\begin{array}{l}\text { Indicar necessidades de estrutu- } \\
\text { ras físicas e recursos pedagógicos }\end{array}$ & D13 & 1 & 3,3 \\
\hline $\begin{array}{l}\text { Prever a formação docente para } \\
\text { a inclusão }\end{array}$ & D16 e D26 & 2 & 6,7 \\
\hline
\end{tabular}

Fonte: os autores.

A categoria Possibilitar a avaliação das limitações e possibilidades dos alunos representou o maior número de menções - 46,7\% (14) - entre os participantes desta pesquisa. Entre elas destacam-se as seguintes falas:

O currículo oficial não pode ser reduzido em relação aos conteúdos que devem ser ensinados aos alunos com e sem NEE, isso seria o empobrecimento do currículo. Numa perspectiva inclusiva o elemento fundamental é a avaliação das limitações e pos- 
sibilidades dos alunos, uma vez que por meio de uma avaliação assertiva o professor poderá adequar os objetivos educacionais de acordo com as necessidades especiais de cada aluno. (D01). Precisa pensar em cada criança em sua dificuldade e seus pontos fortes. (D03).

Avaliar a situação diária dos alunos...a inclusão em si e aspectos relevantes que contribuem para o trabalho docente...não adianta ter um bom currículo e não ter subsídios para efetuá-lo. (D12) (informações verbais).

Segundo Nunes e Madureira (2015, p. 133), a perspectiva da inclusão educacional é, também, uma abordagem curricular, pois “[...] procura minimizar as barreiras à aprendizagem e maximizar o sucesso de todos os alunos e, nessa medida, exige que o professor seja capaz de começar por analisar as limitações na gestão do currículo, em vez de sublinhar as limitações dos alunos." Para que haja essa transição do currículo - de um ato educativo inacessível para o acessível -, exigese o desenvolvimento desses conhecimentos junto aos docentes em seu processo formativo.

Paralelamente, com duas menções entre as respostas obtidas, prever a formação docente para a inclusão foi indicado por D16 e D26 como uma necessidade diante da perspectiva inclusiva.

Precisa contemplar trabalho por níveis de aprendizagem, de forma interdisciplinar, por meio de mediadores, de acordo com o aprendizado de cada sujeito, também, propiciar formação continuada em diversas áreas do conhecimento que promovam elevação de aprendizagem e realcem melhor qualidade de vida do educando e que possibilite a práxis deste, por parte do educador. (D16).

Acho que deve estar atrelado à formação docente para os docentes poderem entender o que é educação inclusiva. Porque às vezes lá está escrito, mas o professor não sabe como faz. Então além do currículo ser claro e trazer a inclusão como um objetivo, devemos pensar na formação dos professores para poder atender essas demandas. (D26) (informações verbais).

Acrescenta-se também que, nas considerações finais do questionário, D13 e D18 indicaram a necessidade formativa para a inclusão como meio para efetivação da inclusão.

É preciso capacitar os profissionais que atuam nas escolas. (D13).

O tema da inclusão é de grande relevância e a demanda tem sido cada vez maior. Infelizmente não são todas as escolas que estão preparadas para atender essa demanda, seja por falta de 
funcionários capacitados ou por orientação, assim como nós professores que temos que administrar uma sala de aula em sua complexidade e não temos a devida orientação. Muitas vezes não temos também uma devolutiva se estamos fazendo um bom trabalho ou não. (D18) (informações verbais).

Em segundo lugar, com 23,4\% (7) de frequência entre as menções feitas pelos docentes, foi apontado que um currículo em uma perspectiva inclusiva precisa abordar questões relativas à realidade da escola e da diversidade no contexto escolar. Dentre os docentes, destacam-se as seguintes falas:

Um currículo que trate de questões como: ideologia, reprodução cultural e social, poder, classe social, representação, cultura, gênero, raça, etnia, sexualidade, multiculturalismo. (D02).

Penso que ele deve prever a organização do trabalho pedagógico visando à aprendizagem de todos, não ser excludente e classificatório, deve contemplar a cultura e a diversidade como elementos que ajudam no processo de ensino e de aprendizagem. (D04) (informações verbais).

Dessa forma, se a educação está subsidiada pela educação inclusiva, as práticas pedagógicas, a organização dos objetivos, os materiais, os métodos e a avaliação do professor são norteados pela diversidade e pelos modos de aprendizagem contidos na sala de aula. Assim, “[...] compreende o currículo como representação das especificidades de todas as crianças, o qual é percebido na necessidade de flexibilização e planificação das necessidades de aprendizagens de um grupo heterogêneo que possuímos em sala de aula.” (PRAIS; ROSA, 2014, p. 367-368).

Comumente, o currículo escolar é um território de tensões globais e não fragmentadas do contexto social em que cada instituição está inserida. Dessa maneira, refletir e pensar o contexto social são prerrogativas elementares na definição de currículo.

Neste sentido, os aspectos relacionados à educação e ao currículo não devem ser percebidos de modo fragmentado, uma vez que necessitam abranger a totalidade de considerações, ou seja, perspectivas mais amplas que explicitem os fatos presentes no interior do espaço escolar como mais um fio de um emaranhado de acontecimentos sociais. (SANTOS; COSTA, 2017, p. 89).

Com 13,3\% (4) de frequência entre as respostas dadas pelos participantes, para a construção de um currículo inclusivo, deve ser considerada a indicação de conceitos e metodologias adequadas para a inclusão. D05 e D11 exemplificam 
esse aspecto em suas respostas ao se reportarem à necessidade de os currículos expressarem conceitos e pressupostos inclusivos, para que o caminho a ser seguido por toda instituição seja claro, em especial aos docentes, a fim de assegurar o direito de todos à educação.

Penso que precisa deixar claro de que vivemos um novo contexto educacional, que temos alunos diferentes, que cada um aprende de uma maneira diferente, possibilita o professor a pensar nessa diversidade e indica metodologias adequadas para inclusão de todos na educação. (D05).

Acho que deve conter o que é inclusão, e como a escola tem se organizar para isso, e também orientações para os professores ensinarem os conteúdos para alunos com deficiência e com dificuldade de aprendizagem. (D11) (informações verbais).

Dessa forma, ressalta-se Silva (2005), o qual pontua que, diante de qualquer concepção curricular, é necessário buscar coerência e clareza entre a definição e a qual objetivo se pretende atingir. Portanto, no caso de um currículo baseado em pressupostos inclusivos, é preciso, primeiramente, expressar sua concepção e seus objetivos para, assim, direcionar de maneira adequada o trabalho pedagógico.

Em decorrência disso, é pertinente que se indague qual corrente de pensamento seria capaz de trazer uma reestruturação da educação, considerando o direito de educação para todos os alunos, suas particularidades, e superando a visão neoliberal da educação. Melero (2013) propõe o Enfoque Histórico-Cultural como forma de construir um currículo sem exclusões. Para isso, é preciso pensar que a:

[...] história do currículo não deve ser focalizada apenas no currículo em si, mas também no currículo como fator de produção de sujeitos dotados de classe, raça, gênero. Nessa perspectiva, o currículo deve ser visto não apenas como a expressão ou a representação ou o reflexo de interesses sociais determinados, mas também como produzindo identidades e subjetividades sociais determinadas. O currículo não apenas representa, ele faz. É preciso reconhecer que a inclusão ou a exclusão no currículo tem conexões com a inclusão ou exclusão na sociedade. (SILVA, 2005, p. 10).

Quanto ao aspecto de orientar a elaboração de currículo adaptado indicado pelo D06 em Orientações aos professores para a elaboração de um currículo adaptado aos casos de inclusão, pois os professores não sabem como fazê-lo, cabe uma ressalva diante da perspectiva da inclusão educacional. O termo currículo adaptado precisa ser tomado com cuidado ao pontuar como uma necessidade na 
inclusão, tendo em vista que a adequação necessária prevista nessa perspectiva está na metodologia e nos recursos pedagógicos a serem utilizados para que o aluno tenha acesso e aprenda os conteúdos elencados pelo currículo (MANTOAN, 2015). Desse modo, as orientações mencionadas por D06 podem referenciar a necessidade de um currículo que preveja a possibilidade do uso de diferentes metodologias e recursos para promover a aprendizagem de todos os alunos, em detrimento de atividades facilitadoras ou minimizadoras do acesso ao currículo escolar.

Somado a isso, outra menção que corrobora os pressupostos inclusivos defendidos por Mantoan (2015) está em considerar o currículo em uma construção coletiva. Essa indicação é expressa por D08 quando expõe que um currículo inclusivo deve considerar: "Uma construção coletiva para um desenvolvimento coletivo em prol dessa ação que não devia ser isolado por uma pessoa só dá escola, pois deve ser ressaltamos que a inclusão faz parte da escola toda." (informação verbal).

Do mesmo modo, Santos, Lopes e Costa (2017) indicam que o entendimento do currículo perpassa pela importância dada na participação dos sujeitos que compõem a comunidade escolar nos processos decisórios em sua constituição.

\footnotetext{
Nas decisões que moldam processos escolares, inclusive o currículo, a presença da comunidade escolar pode ser a garantia de que os conhecimentos escolares expressam proximidades em relação à concepção de homem, mundo e sociedade que interessa aos sujeitos de uma determinada classe social, os quais serão submetidos ao processo educativo. (SANTOS; LOPES; COSTA, 2017, p. 328).
}

Outro aspecto enunciado entre as respostas está na prerrogativa de que, junto ao currículo, é necessário estar atento às estruturas físicas e recursos pedagógicos para que se possa efetivar a inclusão educacional ("Não se tem estruturas físicas, falta materiais pedagógicos.” D13, informação verbal). Tal elemento está permeado nas inquietações geradas pela perspectiva da inclusão educacional, a qual exige não somente mudanças pedagógicas, mas também de estruturas, de financiamento e de investimento, de recursos materiais, pedagógicos e humanos, de gestão, de políticas públicas, entre outros (MANTOAN, 2015). 


\section{CONSIDERAÇÕES FINAIS}

Para finalizar a discussão proposta neste artigo, retoma-se à questão problematizadora: de que maneira professores da Educação Básica percebem a relação entre o currículo e a inclusão educacional?

Em relação ao primeiro objetivo, identificou-se que o currículo expressa um projeto que busca satisfazer as demandas percebidas no contexto social. Consequentemente, o currículo traz consigo um projeto de educação para formar esse sujeito em seu meio social. Desse modo, pensar a inclusão educacional é refletir sobre a necessidade de um projeto social e de educação que atenda às necessidades formativas dos seres humanos para que estes tenham acesso a uma porção de cultura (conhecimentos, cultura) e, assim, aprendam conceitos construídos historicamente pela humanidade.

Compreendeu-se que não existe uma única concepção do que é currículo, mas que cada autor traz uma definição para tal, que são complementares no contexto educacional. Dessa forma, as escolas são responsáveis por um tipo de formação de seus alunos e, portanto, devem efetivar práticas inclusivas por meio de um planejamento curricular.

Assim, o currículo - em uma perspectiva inclusiva - deve ser construído de maneira clara e coesa com os pressupostos que visam assegurar o direito de todos à educação. Dessa maneira, entende-se que quando as intenções inclusivas são sistematizadas pelo currículo, as ações docentes propiciam, por meio da organização do ensino, a mediação qualitativa para promover a aprendizagem dos alunos.

Destaca-se, quanto aos objetivos de apresentar e analisar percepções de docentes da Educação Básica, uma síntese frente às categorias feitas e discutidas neste artigo. Evidenciou-se nesta pesquisa que as representações conceituais que os professores - participantes da pesquisa - tiveram acerca do currículo foram: conteúdos a serem ensinados e aprendidos, experiências de aprendizagem vivenciadas e a serem vividas, planos pedagógicos a serem elaborados pelos professores, escolas e sistemas educacionais e objetivos a serem alcançados por meio do processo de ensino e do processo de avaliação representam a identidade de cada instituição em sua função social e documento orientador da prática pedagógica.

No que se refere à pertinência entre currículo e inclusão educacional, 64\% (19) dos docentes consideraram que, plenamente, o currículo também influencia na efetivação ou não da inclusão, bem como 41\% (13) avaliaram que o currículo de sua 
instituição contempla os pressupostos de uma educação inclusiva. Essa percepção dos participantes denota a relevância dada para a sistematização dos pressupostos curriculares em função de uma educação inclusiva que norteará a prática pedagógica a fim de assegurar o direito de todos à educação.

Ainda sobre os resultados obtidos, na percepção dos docentes quanto aos elementos a serem considerados na construção do currículo inclusivo, destacam-se: possibilitar a avaliação das limitações e possibilidades dos alunos, abordar questões relativas à realidade da escola e da diversidade no contexto escolar, indicar conceitos e metodologias adequadas para a inclusão, orientar a elaboração de um currículo adaptado, ressaltar a necessidade de currículo adaptado, ressaltar a necessidade de uma construção coletiva, indicar a necessidade de estruturas físicas e recursos pedagógicos e prever a formação docente para a inclusão.

\section{REFERÊNCIAS}

AINSCOW, M. Processo de Inclusão é um processo de aprendizado. São Paulo, 2008. Entrevista concedida à Secretaria de Estado de Educação Especial. Disponível em: <http://www.crmariocovas.sp.gov.br/ees_a.php?t=002>. Acesso em: 14 jul. 2017.

BARDIN, L. Análise de conteúdo. São Paulo: Edições 70, 2011.

BRASIL. Constituição. República Federativa do Brasil de 1988. Brasília, DF: Senado Federal, 05 out. 1988. Disponível em: <http://www.planalto.gov.br/ccivil_03/ constituicao/ConstituicaoCompilado.htm>. Acesso em: 20 jun. 2017.

BRASIL. Lei n. 9.394, de 20 de dezembro de 1996. Institui as Diretrizes e Bases da Educação Nacional. Diário Oficial da União, Brasília, DF, 21 dez. 1996. Disponível em: <http://www.planalto.gov.br/ccivil_03/leis/19394.htm>. Acesso em: 14 jul. 2017.

BRITO, K. R. S. Um estudo reflexivo sobre o currículo na educação infantil. Educação Por Escrito, v. 5, n. 1, p. 68-79, jan./jun. 2014. Disponível em: < http://revistaseletronicas.pucrs.br/ojs/index.php/porescrito/article/viewFile/16882/11488>. Acesso em: 14 jul. 2017.

FUENTE, J. R. O. Escuela, Currículum y Sociedad. Revista Teoria e Prática da Educação, v. 14, n. 3, p. 5-15, set./dez. 2011. Disponível em: <http://periodicos. uem.br/ojs/index.php/TeorPratEduc/article/view/18472/9637>. Acesso em: 13 jul. 2017.

GIL, A. C. Métodos e técnicas de pesquisa social. 5. ed. São Paulo: Atlas, 1999. 
GRUNDY, S. Producto o praxis del currículo. Madrid: Morata, 1998.

LEAL, R. B. Planejamento de ensino: peculiaridades significativas. Revista Iberoamericana de Educación, Madri, v. 37, n. 3, 2005.

LÜDKE, M.; ANDRÉ, M. Pesquisa em educação: abordagens qualitativas. 6. ed. São Paulo: EPU, 2012.

MANTOAN, M. T. É. Inclusão escolar: O que é? Por quê? Como fazer? São Paulo: Summus, 2015.

MELERO, M. L. Discriminados pelo currículo por sua desvantagem: estratégias do currículo para uma inclusão justa e factível. In: SACRISTÁN, J. G. (Org.). Saberes e incertezas sobre o currículo. Porto Alegre: Penso, 2013.

MOREIRA, A. F. B.; CANDAU, V. M. Educação escolar e cultura(s): construindo caminhos. Revista Brasileira de Educação, Rio de Janeiro, n. 23, p. 156-168, maio/ ago. 2003. Disponível em: <http://www.scielo.br/pdf/rbedu/n23/n23a11>. Acesso em: 10 jul. 2017.

NUNES, C.; MADUREIRA, I. Desenho Universal para a Aprendizagem: Construindo práticas pedagógicas inclusivas. Da Investigação às Práticas, Lisboa, v. 5, n. 2 , p. 126-143, 2015.

PRAIS, J. L. S.; ROSA, V. F. Organização da atividade de ensino a partir do Desenho Universal de Aprendizagem: das intenções às práticas inclusivas. Revista Polyphonía, Goiânia, v. 25, n. 2, p. 359-374, jun./dez. 2014.

SACRISTÁN, J. G. O que significa o currículo? In: SACRISTÁN, J. G. Saberes e incertezas sobre o currículo. Porto Alegre: Penso, 2013.

SACRISTÁN, J. G. O currículo: uma reflexão sobre a prática. 3. ed. Porto Alegre: Artmed, 2000.

SACRISTÁN, J. G. Poderes instáveis em educação. Porto Alegre: Artmed, 1999.

SANTOS, A. R. J.; COSTA, R. O currículo no contexto da sociedade contemporânea sob a perspectiva de professores da educação básica. Revista Educação em Perspectiva, Viçosa, v. 8, n. 1, p. 89-105, jan./abr. 2017. 
SANTOS, A. R. J.; LOPES, R. P.; COSTA, R. Os sentidos referentes à classe social e relações de poder presentes no contexto das teorias curriculistas tradicionais e críticas. Revista e Curriculum, São Paulo, v. 15, n. 2 , p. 325-344, abr./jun. 2017. Disponível em: <https://revistas.pucsp.br/index.php/curriculum/article/view/26631>. Acesso em: 14 jul. 2017.

SANTOS, M. P. Inclusão. In: SANTOS, M. P.; FONSECA, M. P. S.; MELO, S. C. (Org.). Inclusão em Educação: diferentes interfaces. Curitiba: CRV, 2009.

SILVA, T. T. Documentos de identidade: uma introdução às teorias do currículo. 2 . ed. Belo Horizonte: Autêntica, 2005.

TRAVERSINI, C. S. et al. Currículo e Inclusão na escola de Ensino Fundamental. Porto Alegre: EDIPUCRS, 2013. Disponível em: <http://ebooks.pucrs.br/edipucrs/Ebooks/Pdf/978-85-397-0376-0.pdf>. Acesso em: 14 jul. 2017.

UNESCO. Declaração de Salamanca sobre princípios, políticas e práticas na área das Necessidades Educativas Especiais. Salamanca: UNESCO, 1994. Disponível em: < http://portal.mec.gov.br/seesp/arquivos/pdf/salamanca.pdf > . Acesso em: 14 jul. 2017.

Recebido em: 27 de setembro de 2017

Aceito em: 30 de outubro de 2017

Endereço para correspondência: Rua Reverendo João Batista Ribeiro Neto, 76, 86645-055, Londrina, Paraná, Brasil; jacqueline_lidiane@hotmail.com 